\title{
Outros retratos, outras vozes na narrativa brasileira contemporânea
}

Vera Lúcia de Oliveira ${ }^{1}$

Eu sou aquele que ensina seu filho e não ganha bem, não sabendo se limpa as mãos do pó do giz ou do sangue da exclusão social.

Eu sou aquele que passou por ti na calçada, que você olhou com pena, mas logo pensou em teus problemas que são maiores que minha fome.

Eu sou o povo.

Ferréz

Em 2005, o escritor e rapper Ferréz (nome artístico de Reginaldo Ferreira da Silva) ${ }^{2}$ publica "Terrorismo literário", manifesto de abertura do livro Literatura marginal (2005a). Linguagem contundente, como a de todos os manifestos, construído com frases de efeito, em que a voz enunciadora se cristaliza em um "nós" plural e coletivo, o autor fala em nome da periferia, ou melhor, em nome dos artistas e escritores que vivem às margens, tanto socioeconômica quanto literária e artística. São os excluídos do sistema, por serem pobres e negros em sua maior parte, por terem baixa escolarização ou serem autodidatas, com empregos humildes e mal remunerados. Ferréz reivindica um espaço na literatura e arte brasileiras para esses novos autores; um espaço de visibilidade que não passe pela imagem de violência e brutalidade com a qual a periferia é sempre vista e descrita. Em relação a isso, ele afirma: "não somos o retrato, pelo contrário, mudamos o foco e tiramos nós mesmos a nossa foto" (Ferréz, 2006).

Não é casual o uso do termo "retrato", por Ferréz. Desde o início, nossa literatura se incumbiu do papel, e mesmo da necessidade, de fornecer interpretações do país e de sua história. Esses "retratos" eram pautados por uma arte mimética e, nesse sentido que Luís Augusto Fischer afirma que uma das características mais marcantes da literatura brasileira é a opção dos seus autores pelo realismo, com o objetivo de propor imagens fidedignas do país. Tal realismo, ele afirma, “ajuda a

\footnotetext{
${ }^{1}$ Doutora em língua e literatura ibérica e iberoamericana e professora de literaturas portuguesa e brasileira na Università degli Studi di Perugia, Perugia, Itália. E-mail: veralucia.deoliveira.m@gmail.com

${ }^{2} \mathrm{O}$ nome Ferréz, escolhido pelo autor, reúne dois símbolos do passado: Virgulino Ferreira e Zumbi dos Palmares.
} 
pensar o Brasil, esse mistério que funde abundância natural e miséria social em doses cavalares" (Fischer, 2008, p. 19).

No decorrer do tempo e na alternância das escolas estético-literárias, os nossos escritores propuseram, pois, uma série de retratos nacionais, começando por José de Alencar, com seus romances indianistas, regionalistas e urbanos, passando pelos modernistas, ${ }^{3}$ chegando aos dias atuais, em que essa tendência, embora não mais preponderante, não arrefece. É evidente que tais representações são necessariamente parciais, pois, por mais que os autores busquem uma homologia entre literatura e realidade, toda obra de arte é invenção e criação de universos alternativos. Acrescente-se a isso o fato que, no afã de propor certos aspectos do real com maior veracidade, os autores acabem muitas vezes por deformá-lo, expressionisticamente.

O desejo de elaborar, pois, um retrato social, tão recorrente em nossas letras, é retomado por Ferréz e pelos autores da chamada literatura marginal para afirmar que, se houve uma alteração de foco e no modo como a periferia é hoje representada, ela só foi possível porque mudou o sujeito, mudou o olhar de quem faz o retrato e, assim, o retrato agora é outro.

Resta-nos pôr a questão: como se deu tal alteração? E como podemos definir e enquadrar essa literatura e essa arte que incorporam esteticamente o contexto social das grandes cidades do país e, sobretudo, o imenso território carente das periferias urbanas?

Para entender como o autor chegou a tais formulações, ou seja, de que já existe no Brasil uma literatura diversa e mais inclusiva, é necessário considerar as transformações vividas pela sociedade brasileira nas últimas décadas. Depois de um período de grandes dificuldades, que se seguiu ao fim da ditadura e ao retorno democrático em meados dos anos 1980, o Brasil se afirmou entre as nações industrializadas, uma economia que, embora atualmente em desaceleração, é relativamente forte entre os países do BRICS (Brasil, Rússia, Índia, China e África do Sul).

É bem verdade que, se examinarmos a fundo esse panorama, perceberemos que o crescimento econômico foi em muitos âmbitos mais aparente do que real e que o modelo de capitalismo assimilado tende, não a valorizar as especificidades individuais e de grupo, mas, ao contrário, a

\footnotetext{
${ }^{3}$ Cabe aqui citar que um dos textos básicos desse movimento foi o livro Retrato do Brasil, de Paulo Prado, publicado em 1928.
} 
reduzir o humano à descartabilidade e à irrelevância, perpetuando a disparidade social e provocando novas e dolorosas "catástrofes históricas" (Ginzburg, 2012, p. 203). Este não é, pois, um modelo de desenvolvimento inclusivo; tanto é verdade que as contraposições socioeconômicas, culturais, religiosas e mesmo étnicas nunca se explicitaram de forma tão aberta como nesta época.

Não podemos ignorar, porém, que, segundo a Fundação Getúlio Vargas, cerca de 40 milhões de brasileiros saíram das classes D e E (e até mesmo C) durante os últimos dez anos, $80 \%$ dos quais são afrodescendentes. Parte dessa população vive nos subúrbios das grandes cidades, como São Paulo, Rio de Janeiro, Salvador, Belo Horizonte. Esses dados e números refletem uma certa redução da desigualdade, que não se deve apenas - como supõem alguns - às políticas assistenciais governamentais, que tiveram e têm certamente sua importância, mas ao esforço de milhões de brasileiros, que lutam para melhorar suas condições de vida.

Consequência dessas transformações foi o surgimento de segmentos de uma nova classe, que, em concomitância com o papel social e a importância que adquiriu na economia de mercado, quer contar também do ponto de vista cultural e político. Assistimos, assim, a um fenômeno importante, ligado ao fato de que grupos secularmente excluídos pobres, negros, índios - buscam e forjam espaços de visibilidade e representação literária e artística, provocando uma significativa mudança no cenário nacional.

Retornemos ao que foi dito acima acerca do papel civilizacional e unificador que teve a literatura brasileira, em um país que emergira da condição colonial apenas em 1822, com um futuro inteiramente por construir. Coube ao escritor brasileiro, em vários momentos de nossa história, formular representações da identidade nacional a partir de uma colcha de retalhos, que era e é o tecido social do país. Certamente esses "retratos" não foram neutros nem isentos. Onde está o negro na literatura romântica? E o índio, presente nas obras do período, correspondia à imagem real do autóctone que estava sendo dizimado em várias regiões do país? Quando Ferréz afirma "não somos o retrato" está simplesmente constatando que nossa literatura deixou de fora inteiras faixas da população.

Regina Dalcastagnè, no artigo "A personagem do romance brasileiro contemporâneo", publicado em 2005, afirma que na narrativa brasileira 
contemporânea são geralmente ausentes dois grandes grupos sociais, os pobres e os negros, que, acrescenta, correspondem em grande parte aos habitantes das periferias urbanas. (Dalcastagnè, 2005, p. 14). A pesquisadora aborda, em uma articulada e ampla pesquisa, a produção ficcional nacional de 1990 a 2004. Analisando 258 romances, ela chega à surpreendente conclusão de que a literatura brasileira continua, hoje, a ser uma atividade predominantemente masculina, praticada em 93\% dos casos por autores brancos: "Os números, indicam com clareza, o perfil do escritor brasileiro. Ele é homem, branco, aproximando-se ou já entrado na meia idade, com diploma superior, morando no eixo Rio-São Paulo" (Dalcastagnè, 2005, p. 33).

É justamente para preencher esse déficit de representação, em todos os níveis, desde o artístico-literário ao político, e em consonância com as transformações econômicas e sociais do país, que nasceram na década de 1980, nos bairros mais pobres e periféricos das metrópoles brasileiras, numerosos grupos de hip-hop, inspirados no movimento hip-hop norteamericano. Combinando vários gêneros artísticos, tais como música, poesia, pintura e dança, buscaram trazer à tona a voz silenciada da população que vive às margens. Muitos são os nomes e os grupos de hiphop (assim como os de rap) que se impuseram no cenário nacional e exercem grande fascínio sobre o público jovem. Entre eles, podemos citar os Racionais MC's, bem como os rappers Mano Brown, Emicida, Edi Rock e Criolo, este último, aliás, entre os nomes mais originais surgidos no atual panorama musical brasileiro. Tais artistas abordam em suas composições o quotidiano violento dos subúrbios, a pobreza, a precariedade em que vivem tantos indivíduos, a repressão policial, as invasões e guerras entre gangues pelo controle do território. Abordam também a força e a energia criativa dessa população, o desejo de participação, a necessidade e a exigência de autorrepresentação, a partir de uma ótica diferente, que não identifique necessariamente o excluído, o periférico, o favelado e o marginal como um ladrão ou um delinquente.

Tendo presente esse panorama, podemos entender melhor o conto "Pensamentos de um correria", de Ferréz, publicado em 2007, pela Folha de S. Paulo, e a enorme polêmica que gerou. O texto de Ferréz foi uma espécie de resposta a um artigo de Luciano Huck, que saíra no mesmo jornal uma semana antes, intitulado "Pensamentos quase póstumos", no qual o noto apresentador televisivo narrava a chocante experiência de um assalto à mão armada, por ele vivenciada em São Paulo. Retomando a 
cena, em seu conto, e invertendo a ótica com que tudo é visto e narrado, Ferréz chocou os leitores. Ao incorporar o contexto urbano e as razões socioeconômicas que induzem à violência, ele foi acusado de minimizar ou de justificar o assalto, tendo sido aberto contra ele um inquérito em dezembro de 2007, por apologia ao crime.

Na realidade, o que faz Ferréz nesse conto é inverter o foco da narrativa, apontando para a necessidade, em nossa arte e literatura, de novas e mais abrangentes leituras e interpretações da sociedade atual. Em resposta à indignação de Luciano Huck pela violência vivida, Ferréz poderia ter enviado à redação do jornal uma carta, ou mesmo um texto jornalístico, em que argumentasse sobre as responsabilidades sociais e políticas de um país que permite que a violência seja quase a única modalidade de relação entre as classes sociais. No entanto, nada teria sido tão eficaz quanto ter usado seu texto como proposta e mesmo como modelo possível de uma nova literatura, e nova - note-se - não porque caracterizada por uma linguagem de ruptura, mas porque nos arranca bruscamente da nossa cadeira de leitores acomodados e nos leva pelos meandros de uma consciência e de um corpo lacerados pelo rejeito de quem "ganhou logo cedo um kit pobreza", como afirma o narrador do breve e incisivo conto:

Era da seguinte opinião: nunca iria num programa de auditório se humilhar perante milhões de brasileiros, se equilibrando numa tábua pra ganhar o suficiente pra cobrir as dívidas, isso nunca faria, um homem de verdade não pode ser medido por isso. Ele ganhou logo cedo um kit pobreza, mas sempre pensou que, apesar de morar perto do lixo, não fazia parte dele, não era lixo (Ferréz, 2007).

Com a voz narrativa em terceira pessoa e uma focalização interna, seguimos a jornada do "correria", 4 provamos sua vergonha pelo desprezo com que é tratado e, a partir dessa posição incômoda, já não nos parece absurdo questionar, como faz o protagonista do conto, "como alguém pode usar no braço algo que dá pra comprar várias casas na sua quebrada" (Ferréz, 2007).

Quando publicou esse texto, Ferréz já era relativamente conhecido como expoente da chamada literatura marginal. Fundador do Grupo 1DaSul, interessado em promover atividades e encontros em favor dos

\footnotetext{
${ }^{4}$ Termo usado para definir quem vive de expedientes e furtos.
} 
habitantes de seu bairro e de outros da capital paulista, Ferréz (1975) nasceu e cresceu em São Paulo, no bairro do Capão Redondo, um dos mais degradados e violentos da cidade.

Em 1997, ele publicou o primeiro livro, uma coletânea poética intitulada Fortaleza da desilusão, seguido de Capão pecado (2000/2005b), que o revelou ao público, Manual prático do ódio (2003) e, ainda, Amanhecer Esmeralda (2005), Ninguém é inocente em São Paulo (2006) e Deus foi almoçar (2012). Muitos de seus contos foram traduzidos em vários países, entre eles Itália, Alemanha, Portugal, Espanha e França. Autodidata, antes de chegar à literatura, exerceu várias atividades, como a de pedreiro e vendedor de porta em porta. Afirma que foram os livros que o salvaram, porque deram um sentido à sua vida, canalizando de forma construtiva sua revolta.

O percurso de Ferréz tem muitas semelhanças e afinidades com o de Carolina Maria de Jesus (Sacramento, 14/03/1914 - São Paulo, 13/02/1977), cujo livro Quarto de despejo, publicado em 1960, vendeu em pouco tempo cerca de 100 mil cópias e foi traduzido em 29 idiomas, tornando-se um fenômeno literário no Brasil e no exterior. Mulher negra, pobre, semianalfabeta, moradora da favela do Canindé, situada na marginal do Rio Tietê, em São Paulo, Carolina, para viver e garantir o sustento dos filhos, recolhia papel, vidro e ferro velho para vender. Quarto de despejo é uma espécie de diário, em que ela anota momentos e acontecimentos do seu dia a dia, passado, no mais das vezes, na angústia de buscar o essencial para a sua sobrevivência e a dos três filhos, em um ambiente difícil e degradado:

Levantei de manhã triste porque estava chovendo. [...] O barraco está numa desordem horrível. É que eu não tenho sabão para lavar as louças. Digo louças por hábito. Mas é as latas. Se tivesse sabão eu ia lavar as roupas. Eu não sou desmazelada. Se ando suja é devido a reviravolta da vida de um favelado. Cheguei à conclusão que quem não tem de ir pro céu, não adianta olhar para cima. É igual a nós que não gostamos da favela, mas somos obrigados a residir na favela (Jesus apud Oliveira, 2007a, p. 32-33).

Ia pensando: será que Deus vai ter pena de mim? Será que eu arranjo dinheiro hoje? Será que Deus sabe que existe as favelas e que os favelados passam fome? (Jesus apud Oliveira, 2007a, p. 36). 
Os fatos narrados abrangem um período que vai de julho de 1955 a maio de 1960. A autora escrevia em folhas de cadernos que ela mesma confeccionava, utilizando o papel que recolhia. Foi descoberta casualmente pelo jornalista Audálio Dantas, que fazia uma reportagem em sua favela.

Carolina Maria de Jesus chegou a publicar outros livros, que não obtiveram a mesma repercussão, mas que revelam uma verdadeira vocação literária. Não obstante os parcos recursos dos quais dispunha (tinha só dois anos de escolarização), ela compôs um quadro vibrante e intenso da vida de uma mulher inteligente e forte, para a qual a literatura era não apenas o resgate de sua condição de indigente, mas o próprio sentido de sua existência. Com o sucesso obtido com o primeiro livro, ela comprou uma casa de alvenaria, mas acabou voltando, nos últimos anos, para a favela de onde saíra, pois, passado o momento da novidade, ela foi esquecida pela mídia que a lançara, tendo falecido, infelizmente, na mesma condição que, durante toda sua vida, quisera deixar. ${ }^{5}$

Como as páginas de Quarto de despejo, de Carolina de Jesus, também os textos de Ferréz estão a meio caminho entre a narrativa literária e o relato autobiográfico. Muitos dos protagonistas de seus livros são inspirados em personagens reais, amigos ou conhecidos de seu bairro. Não há, assim, distanciamento marcado entre autor, narrador e personagens: todos são oriundos do mesmo território desprestigiado, que é periferia do consumismo, periferia social, econômica e política das cidades brasileiras.

Nas dedicatórias, nos agradecimentos, nas notas introdutórias às suas obras, bem como nas entrevistas que deu, Ferréz defende sua opção de falar sobre o mundo em que cresceu e de falar a partir de uma ótica interna, com o conhecimento dos fatos, contestando a imagem superficial e estereotipada que a sociedade em geral tem da periferia.

No livro Ninguém é inocente em São Paulo (2006), significativo já a partir do título, as breves narrativas, muitas vezes chocantes pelos temas e pela linguagem usada, mostram bem essa inversão de enfoque sobre a qual fala o seu autor. Na nota introdutória do livro, Ferréz afirma que as histórias são

Trechos de vida que catei, trapos de sentimentos que juntei, fragmentos de risos que roubei estão todos aí, histórias diversas

\footnotetext{
${ }^{5}$ Além de Quarto de despejo (1960), a autora publicou os livros Casa de alvenaria (1961), Diário de Bitita (1980, na França; 1986, no Brasil, póstumo) e Meu estranho diário (1996, póstumo).
} 
do mesmo ambiente, de um mesmo país, um país chamado periferia. Pessoas na maioria já falecidas, eternizadas no meu universo. Eternos amigos que continuam a me contar suas histórias, que sempre estão ao meu lado (Ferréz, 2006, p. 10).

Como dissemos, Ferréz é expoente da literatura marginal, assim chamada porque se desenvolveu nas periferias, com o objetivo de incorporar temas e figuras relacionadas a esse universo. Afirma o autor: "A literatura marginal sempre é bom frisar é uma literatura feita por minorias, sejam elas raciais ou socioeconômicas. Literatura feita a margem dos núcleos centrais do saber e da grande cultura nacional, ou seja os de grande poder aquisitivo" (Ferréz, 2005a).

Note-se que o eu-lírico da literatura marginal é um eu múltiplo, que não representa só o indivíduo, mas todo o seu grupo social, conforme afirma o crítico Adélcio de Souza Cruz, acrescentando que um dos elementos mais característicos dessa literatura é o seu tom pedagógico, comum ao rap, em que se busca transmitir valores positivos para a comunidade, valores que sejam capazes de fortalecer a autoestima individual e de grupo (Cruz, 2009, p. 171-172).

É interessante observar também que na literatura brasileira o termo marginal já tinha sido utilizado, nos anos 1970, quando um grupo de jovens escritores, oriundos da classe média e com formação culta, criou um movimento que buscava abrir alternativas e circuitos novos de publicação e circulação de livros. Tais autores, também definidos como geração mimeógrafo, produziam seus textos em pequenas edições e de forma quase artesanal, distribuindo-os em vários locais, como universidades, teatros, cinemas. Entre os principais nomes, estão Francisco Alvim, Antônio Carlos de Brito (Cacaso), Torquato Neto, Chacal, Waly Salomão, Ana Cristina Cesar e outros. O movimento "não insiste tanto na renovação das formas estéticas, mas propõe uma mudança nas práticas culturais, nos modos de conceber a cultura fora de parâmetros sérios e eruditos", configurando-se tal atitude como uma crítica ao sistema de produção e fruição da arte e da literatura (Oliveira, 2011, p. 31).

De imediato, vemos que, se os autores que hoje definem a própria produção artística e literária como "marginal" compartilham algo dessa atitude crítica dos anos 1970, também fica evidente que eles têm origem, posição, formação e objetivos completamente diferentes e que suas contestações não se dirigem apenas ao campo artístico-literário, mas à 
inteira estrutura social, econômica e política da sociedade brasileira, vista como geradora e perpetuadora das desigualdades que assolam o país.

De fato, que o trabalhador de baixa renda e escassa escolarização, frequentemente morador das favelas, produza arte e literatura constitui, no mínimo, dentro dessa estrutura econômico-social, reflexo do capitalismo avançado, um contrassenso, aliás, um dissenso em um sistema em que o trabalhador subalterno deve capitalizar inteiramente seu tempo e suas energias para produzir bens e/ou adquirir mercadorias. A arte "pobre", entendida não como carente de significância e valor, mas como arte do pobre, dificilmente pode ser explorada comercialmente, pelas leis da oferta e da procura do mercado, e não é casual que um artista como Criolo tenha levado vinte anos para ter seu primeiro sucesso nacional e internacional e galgar os palcos ao lado de artistas renomados, como Caetano Veloso, com a música Não existe amor em S.P., presente no CD Nó na orelha, lançado em 2011. Notese, aliás, a semelhança e a afinidade entre os títulos dos dois artistas Ninguém é inocente em São Paulo, de Ferréz, e Não existe amor em S. P., de Criolo -, ambos focados na capital paulista.

Como já comentamos, os protagonistas dos livros de Ferréz, ou pelo menos dos livros Capão Pecado e Ninguém é inocente em São Paulo, são os habitantes da "periferia/favela/gueto" (Ferréz, 2005a), termos que o autor funde como se definissem a mesma e indistinta realidade social. Ele afirma, contudo, que não quer usar a favela ou seus moradores como meros motivos literários ou pano de fundo de suas obras; em outras palavras, não quer apenas tematizar a periferia, geralmente vista como o lugar da violência e da delinquência. Isso já o faz a televisão e o cinema, que exploram comercialmente a atração que o público parece ter por cenas e temas cruentos. A sua, ao contrário, quer ser literatura crítica, empenhada e incômoda, quer ser a voz de quem não teve antes acesso à palavra. Tirando do anonimato tantas histórias e vidas, silenciadas na impossibilidade de sair da condição de carência e precariedade, o autor está incorporando à cultura nacional um espaço e um sujeito periféricos, que representam um outro país dentro do país.

É necessário, ainda, considerar que o autor deseja escrever também, e sobretudo, para as periferias e propor uma arte crítica para os que não têm acesso a uma escola de elite, usando a literatura como um motor de transformação social. 
Ter acesso à voz significa, em muitos textos, ver reproduzida a língua falada pelos que normalmente não dominam a norma culta, embora nem por isso comuniquem menos. Ferréz parece ter uma aguda consciência de tal questão, pois a língua é um elemento utilizado para discriminar o habitante da favela. Ele reivindica, por isso, o uso da linguagem popular e da gíria da favela até mesmo em situações formais ou nas relações fortemente hierárquicas, em que é geralmente admitido apenas um registro linguístico culto. No evento "Linguagens da violência, violência da linguagem", organizado em 2001, pelo Consulado Geral da França em parceria com o SESC, a Unesco e a Prefeitura de São Paulo, o autor assim se exprime:

Eu escrevo dessa forma tá ligado, defendo isso assim, porque é o que eu sei fazer. Mas não deixo de fazer na norma culta assim. Já escrevi textos para várias revistas que eu não usei nenhuma gíria [...]. João Antônio que sempre fala né mano: o bom malandro sabe a hora de falar a gíria. Então, tipo quando eu vou fazer palestra pro meu povo eu num falo muita gíria, tá ligado, troco ideia mais na moral, porque eu sei que eles me entendem. Não precisam ficar ouvindo 'tá ligado' o tempo todo (Ferréz, 2001).

Wilma Costa, comentando a "linguagem de gueto" utilizada pelo autor e a afirmação deste - "Eu quero que o maloqueiro leia o meu livro e não esbarre em nenhuma palavra complicada" (Ferréz, 2000) - afirma que o problema surge, na verdade, para o leitor que não pertence a esse mesmo mundo dos narradores e protagonistas dos livros de Ferréz. No entanto, acrescenta a crítica literária, os termos dessa linguagem acabam sendo compreendidos pela repetição de situações em que são usados e, em vez de prejudicar a compreensão textual, tal linguagem "só amplia sua expressividade" (Costa, 2014, p. 15).

A crítica se divide na avaliação da obra de Ferréz. Se alguns estudiosos destacam a novidade de uma voz que, a partir de uma posição subalterna, desafia o sistema literário, seus códigos e normas, outros apontam as limitações e simplificações nos enredos de seus livros e o escasso domínio das técnicas narrativas, alertando para o perigo de que um equivocado paternalismo se insinue na avaliação objetiva de tal produção. O próprio autor tem consciência disso, quando afirma: “Não acho que tudo que vem da periferia é bom. Tem cinema que é bom, tem cinema que é ruim; tem literatura que é boa; tem literatura que é ruim" (Ferréz, 2013). E admite que houve uma evolução em sua obra: 
Eu achava que o assunto era mais importante do que a qualidade do texto, acho ainda que o autor tem um cunho social, o assunto é muito importante, mas a qualidade do texto também é a nossa ferramenta. Então, a gente tem que se aprimorar. Hoje sou um cara que estuda muito mais do que estudava lá atrás (Ferréz, 2013).

O que é interessante aqui, no entanto, não é apenas considerar a qualidade estética dessa prosa (que, todavia, é patente, em muitos dos textos do autor), mas a obra vista como manifestação de uma necessidade vital de fazer literatura, por parte de quem, deliberadamente, não é posto em condições de fazê-lo.

E aqui, vale citar as palavras do crítico João Cezar de Castro Rocha, numa entrevista em que fala da barreira que muitos professores e estudiosos erigem contra a produção dos autores da periferia, afirmando que se tornaram necessários um novo instrumental teórico, novos modelos de análise para interpretar uma literatura cuja voz narrativa pertence ao universo por ela retratado e se identifica com ele:

O problema central é que precisamos ler com muito cuidado esses textos e sobretudo prestar uma atenção renovada a essa expressão cultural. Sem aprisioná-las num modelo teórico e crítico [...]. Eu não posso ler esses escritores com um instrumental teórico criado há mais de 30 anos, nas universidades. O que eles estão propondo e o que estão fazendo é algo realmente novo. Ou eu aceito o desafio de tentar dizer algo de inteligente sobre o que estão produzindo ou eu teria a falsa inteligência de alguns acadêmicos, colegas meus, que têm um discurso pronto para tudo. Aí você pergunta: mas você leu Paulo Lins, você leu o Ferréz? E respondem: “Ah, isso não, porque não é alta literatura". Se eles não querem ler Paulo Lins e Ferréz é uma opção que eu respeito. Mas então fiquem calados (Rocha, 2007).

Nesse sentido, cabem aqui também as palavras de Jaime Ginzburg, em um artigo de 2012, no qual propõe o estudo de autores que pouco despertam a atenção da crítica universitária, como Renato Tapajós, Raduan Nassar e Caio Fernando Abreu, por colocarem-se em uma posição não canônica em relação ao corpus literário nacional, por serem vozes dissonantes, "constrangedoras, desconfortáveis":

Se existem ruínas de catástrofes históricas, é importante que elas sejam observadas, e que delas emanem questões sobre o passado. A literatura, em busca de uma poética dos restos, ganha potência 
expressiva e permite empatia com aqueles que viveram o Brasil como espaço de repressão ou trauma (Ginzburg, 2012, p. 204).

Para esse crítico, "caberia à teoria da literatura uma renovação de vocabulário, perspectiva e metodologia, para confrontar o desafio de caracterizar o que mudou na construção de narradores, e em que se distinguem as formas recentes e as configurações tradicionais" (Ginzburg, 2012, p. 204).

Na verdade, autores como Carolina Maria de Jesus e Ferréz, entre outros, colocam um problema de enorme alcance para o sistema literário brasileiro. Se a escola de qualidade, ou até mesmo a escola básica, é garantida apenas para uma elite - que se autorrepresenta e que propõe tal imagem como um modelo para a sociedade como um todo -, como poderão os milhões de indivíduos que não fazem parte desse círculo privilegiado desenvolver ou expressar suas potencialidades, não só literárias e artísticas, mas de qualquer outro gênero? Ferréz levanta a voz e se apodera do microfone justamente por isso, mas descobre logo que não basta ter o microfone nas mãos, pois se não se sabe usá-lo de maneira eficaz, não se é levado a sério e nem ouvido.

Esse é provavelmente o motivo que levou o autor, em seu último romance, publicado em 2012, sobre o qual se debruçou com afinco por sete anos, a tentar romper com a imagem de escritor de um único tema. Deus foi almoçar, de fato, do ponto de vista do espaço narrativo, pode ser ambientado em qualquer grande cidade e a associação com o mundo e o contexto de Capão Redondo se diluiu em função de uma maior preocupação do autor em tornar suas histórias mais universais. Também o enredo é mais complexo, com personagens que têm, como afirma Ferréz, a violência tão incorporada em suas vidas que não é necessário explicitá-la e ou chocar o leitor com cenas cruentas.

Ferréz não é, como vimos, o único autor que trata de temas ligados à chamada literatura marginal. Embora não se enquadrem nesse rótulo nem se identifiquem com ele, outros escritores abordam temas semelhantes em suas obras. Há mesmo uma vertente, ou, se preferirmos, uma tendência a eleger um foco narrativo alternativo, na maior parte das vezes urbano, em que se questiona a desigualdade social brasileira, a discriminação contra negros e pobres, a homofobia, a degradação ambiental, a impunidade e a violência. Tais autores, e entre eles, além de Ferréz e Paulo Lins, podemos citar Fernando Bonassi, Luiz Ruffato, Conceição Evaristo, Maria Valéria Rezende, Rubens Figueiredo 
e outros indagam sobre questões análogas em muitas de suas obras, centradas em conflitos e situações dramáticas características das cidades brasileiras, das quais traçam um quadro muitas vezes chocante.

O risco dessa literatura é de espetacularizar a violência, já tão explorada pela indústria cultural, produzindo no público o efeito oposto ao desejado, ou seja, o de favorecer, paradoxalmente, uma aceitação das desigualdades sociais por fornecerem uma leitura do sujeito periférico como alguém incapaz de respeitar leis e normas de convivência da sociedade civil. Acerca disso, Tânia Pellegrini afirma:

Estetizar a violência tem sido, na verdade, criar condições excitantes para a velha fruição de um mórbido deleite; mais uma vez o terror e a piedade, a atração e a repulsa, a aceitação e a recusa reforçam os estereótipos em que o pobre e o feio sempre aparecem como risco e ameaça, pois sua contextualização histórica e social desaparece (Pellegrini, 2004, p. 26).

Ferréz tem consciência disso e em seus textos se propõe, como dissemos, a desconstruir a equação pobre-marginal-bandido, tentando inverter a ótica com a qual a violência é narrada. No já citado conto "Pensamentos de um correria", que tanto chocou os leitores ao dar voz e visibilidade a um personagem que vive de expedientes e furtos, praticando amiúde a violência, o narrador provavelmente considerou o fato de que seria muito difícil que o leitor brasileiro se identificasse ou mesmo demonstrasse empatia com o personagem. No entanto, o "correria" se impõe com sua força e presença no cenário urbano, chamando nossa atenção para seu mundo e questionando também a legitimidade do nosso. Conduzindo-nos a seu universo periférico, esse personagem evidencia que a violência não começa nele, com ele ou com o seu gesto de furtar um relógio caro, a violência é a da cidade lacerada e brutal, com seus desvãos, com seus bolsões de miséria, suportados e considerados normais para quem vive em outros bairros. Esse narrador nos interroga sobre o porquê de nos chocar muito mais a violência sofrida por um personagem televisivo do que a causada pela desigualdade, pela discriminação e pela criminalização de milhões de pobres.

Não é, pois, uma teatralização ou estetização da violência o que buscam Ferréz e outros autores da literatura marginal, mas, ao contrário, a própria redefinição do conceito de violência a partir de uma inversão de foco, necessária, afirma Wilma Costa, para que compreendamos esses novos textos: 
Daí a importância de romances que falem de dentro do acontecimento, do meio dos tiroteios, através de testemunhas e sobreviventes do caos, como o caso de Ferréz. Nada poderá ser compreendido do momento em que vivemos, se o ilógico, o sem sentido, e o silêncio dessas vozes não se fizerem ouvir (Costa, 2014, p. 15).

Se Ferréz, como Carolina Maria de Jesus, destoa do cânone clássico da literatura nacional, ele nos traz problemáticas e questões imperiosas, que serão, sempre mais, objeto de estudo dos pesquisadores. São vozes "cuja legitimidade para produzir literatura é permanentemente posta em questão [...], vozes que tencionam, com sua presença, nosso entendimento do que é (ou deve ser) o literário" (Dalcastagnè, 2012, p. 12).

O tema é amplo e articulado, e outros autores assomam nesse vasto panorama. Nosso objetivo não era - nem poderia ser - o de exaurir em poucas páginas toda a complexidade que esses novos sujeitos literários impõem à teoria da literatura, mas o de fornecer elementos que nos ajudem a refletir sobre a emergência dessas vozes sociais, que forçam e forjam seu espaço no campo literário e exigem serem ouvidas e interpretadas dentro do conjunto de representações sobre o Brasil. São autores que abordam temas ligados ao cotidiano, como vimos, com uma ótica inclusiva também das faixas da população brasileira deixadas às margens nos processos decisórios e de divisão da renda no país, população que, no entanto, não quer e não vai mais consentir representações de fora para dentro, repletas de estereótipos que justifiquem a desigualdade brasileira.

\section{Referências}

COSTA, Wilma (2014). Aos que ainda sonham. Rascunho, Curitiba, n. 167, p. 15, mar. Disponível em: https://goo.gl/Jkdj7m. Acesso em: 8 jul. 2014.

CRUZ, Adélcio de Souza (2009). Narrativas contemporâneas da violência: Fernando Bonassi, Paulo Lins e Ferréz. Tese (Doutorado em Letras) - Universidade Federal de Minas Gerais, Belo Horizonte. Disponível em: https://goo.gl/T1eBil. Acesso em: 8 jun. 2013.

DALCASTAGNÈ, Regina (2005). A personagem do romance brasileiro contemporâneo: 1990-2004. Estudos de Literatura Brasileira Contemporânea, Brasília, n. 26, p. 13-71, jul./dez. 
DALCASTAGNÈ, Regina (2012). Literatura brasileira contemporânea: um território contestado. Vinhedo: Horizonte; Rio de Janeiro: Editora da Universidade do Estado do Rio de Janeiro.

FERRÉZ (2013). Ferréz é o entrevistado do Provocações. TV Brasil. On-line. Disponível em: https://goo.gl/11B2Wx. Acesso em: 24 jun. 2014.

FERRÉZ (2000). A revolução tem de ser feita, pela arte ou pelo terror. Folha de $S$. Paulo, São Paulo, 22 jul. Disponível em: https://goo.gl/nK8Rqu. Acesso em: 8 jul. 2014.

FERRÉZ (2001). Mesa-redonda Linguagens da violência, violência da linguagem. In: CICLO CULTURA E SOCIEDADE: as linguagens da violência. São Paulo, 13 set. SESC, UNESCO e Consulado Geral da França de São Paulo. Disponível em: https://goo.gl/YlOZ1S. Acesso em: 30 jan. 2013.

FERRÉZ (2003) Manual prático do ódio. Rio de Janeiro: Objetiva.

FERRÉZ (2005a). Terrorismo literário. In: FERRÉZ (Org.). Literatura marginal: talentos da escrita periférica. Rio de Janeiro: Agir. Disponível em: https://goo.gl/lVWvqG. Acesso em: 25 maio 2013.

FERRÉZ (2005b) Capão Pecado. Rio de Janeiro: Objetiva.

FERRÉZ (2006). Ninguém é inocente em São Paulo. Rio de Janeiro: Objetiva.

FERRÉZ (2007). Pensamentos de um correria. Folha de S. Paulo, 8 out., Seção Tendências/ Debates. Disponível em: https://goo.gl/9PIvLm. Acesso em: 24 jun. 2013.

FERRÉZ (2012). Deus foi almoçar. São Paulo: Planeta.

FERRÉZ (s.d.). Blog do autor. On-line. Disponível em: http:/ / ferrez.blogspot.com.br/. Acesso em: 24 jun. 2014.

FISCHER, Luís Augusto (2008). Literatura brasileira: modos de usar. Porto Alegre: L\&PM.

GINZBURG, Jaime (2012). O narrador na literatura brasileira contemporânea. Tintas. Quaderni di letterature iberiche e iberoamericane, Milano, n. 2, p. 199-221. Disponível em: https://goo.gl/DIrBUP. Acesso em: 20 jul. 2015.

HUCK, Luciano (2007). Pensamentos quase póstumos. Folha de S. Paulo, Seção Tendências/Debates. $1^{\circ}$ out. On-line. Disponível em: https://goo.gl/SZP1qa. Acesso em: 2 maio 2013.

OLIVEIRA, Nelson de et al. (2007a) Cenas da favela: antologia. Rio de Janeiro: Geração. 
OLIVEIRA, Rejane Pivetta de (2011). Literatura marginal: questionamentos à teoria literária. Ipotesi, Juiz de Fora, v. 15, n. 2, p. 31-39, jul./dez.

PELLEGRINI, Tânia (2001). A ficção brasileira hoje: os caminhos da cidade. Revista de Crítica Literária Latinoamericana, Lima-Hanover, ano 27, n. 53, p. 115-118.

PELLEGRINI, Tânia (2004). No fio da navalha: literatura e violência no Brasil de hoje. Estudos de Literatura Brasileira Contemporânea, Brasília, n. 24, p. 15-34, jul./dez.

ROCHA, João César de Castro. (2007). Desafio ao malandro. Época, São Paulo, n. 487, 17 set. Disponível em: https://goo.gl/w9ywBH. Acesso em: 12 out. 2013.

Recebido em abril de 2016.

Aprovado em agosto de 2016.

\section{resumo/abstract/resumen}

\section{Outros retratos, outras vozes na narrativa brasileira contemporânea}

Vera Lúcia de Oliveira

Neste artigo abordo a questão da emergência de novas vozes socias, antes excluídas das representações artístico-literárias nacionais, que assomam com ímpeto e querem contar no panorama da literatura brasileira contemporânea. Entre essas vozes, que têm como precursora Carolina Maria de Jesus, focalizarei brevemente a obra de Ferréz.

Palavras-chave: Ferréz, Carolina Maria de Jesus, Literatura brasileira contemporânea, Literatura e periferia; Prosa urbana

\section{Other outlook, other speakers in the contemporary Brazilian narrative}

Vera Lúcia de Oliveira

In this article I address the issue of the urgent need for new social actors, formerly excluded from national artistic and literary representations, that are now emerging in growing numbers and are playing an increasingly significant role in contemporary Brazilian literature scenario. Carolina Maria de Jesus is a pioneer of this emerging literary expression. In this essay, I will briefly focus on how Ferréz's literary work is emblematic of this type of cultural expression. 
Keywords: Ferréz, Carolina Maria de Jesus, contemporary Brazilian literature, literature and suburbs, urban prose.

\section{Otras imágenes, otras voces en la narrativa contemporánea brasileña}

Vera Lúcia de Oliveira

En este artículo abordo el tema de la aparición de nuevas voces sociales, antes excluidas de las representaciones artístico-literarias nacionales, que se asoman con ímpetu y quieren hacerse notar en el panorama de la literatura brasileña contemporánea. Entre estas voces, que tienen como precursora a Carolina Maria de Jesus, me centraré brevemente en la obra de Ferréz.

Palabras clave: Ferréz, Carolina Maria de Jesus, literatura brasileña contemporánea, literatura y periferia; la prosa urbana. 